\title{
Periostin as a marker of mucosal remodelling in chronic rhinosinusitis*
}

\author{
Jareen A. Ebenezer',2, Jenna M. Christensen'1, Brian G. Oliver², Rema A. \\ Oliver ${ }^{3}$, Gavin Tjin², Jacqueline Ho' , Al-Rahim R. Habib', Janet Rimmer 1,2,4, \\ Raymond Sacks ${ }^{5,6}$, Richard J. Harvey ${ }^{1,5}$

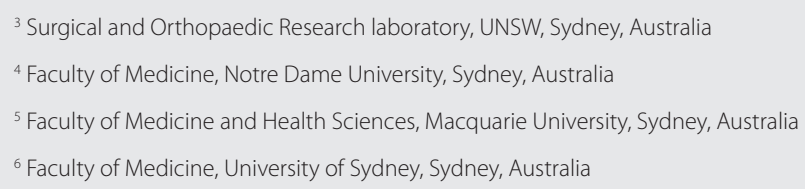

Rhinology 55: 234-241, 2017

https://doi.org/10.4193/Rhino16.215

*Received for publication:

July 10, 2016

Accepted: April 20, 2017

\begin{abstract}
Background: Although extracellular matrix (ECM) proteins are associated with irreversible lower airway changes, the relationship with upper airway remodelling which occurs during chronic rhinosinusitis (CRS) is poorly understood. This study assessed the expression of ECM proteins periostin, fibulin-1, fibronectin and collagenIV in nasal mucosa of patients with and without histologic features of remodelling.
\end{abstract}

Methods: A cross-sectional study of sinonasal mucosal biopsies taken from patients, undergoing surgery for CRS was performed, where patients were grouped according to remodelling, defined by basement membrane thickening (BMT>7.5 $\mu \mathrm{m}$ ) and subepithelial fibrosis. An overall view and three random fields of immunostained tissue sections that included epithelium, basement membrane and submucosa, were imaged using Zeiss Zen software. The area and intensity of positive staining were scored by two blinded observers, using a 12-point ordinal scale of weak to strong.

Results: 65 patients ( $47.6 \pm 13.4$ years, $44.6 \%$ female) were assessed. Patients were grouped as controls $26.2 \%$, BMT/no fibrosis $38.5 \%$ or BMT and fibrosis $33.8 \%$. Stronger grade of periostin expression was associated with remodelling changes and tissue eosinophilia>10/HPF. Fibulin-1, fibronectin and collagenIV did not differ.

Conclusion: Periostin expression was associated with the presence of BMT, fibrosis and tissue eosinophilia; and may identify patients undergoing remodelling changes.

Key words: extracellular matrix proteins, remodelling, chronic rhinosinusitis, periostin, eosinophils

\section{Introduction}

Chronic rhinosinusitis(CRS) encompasses a spectrum of disease with multiple pathogenic factors and inflammatory mechanisms (1), some of which are still not fully understood. CRS, especially with nasal polyps or eosinophilia, is particularly difficult to treat, as current successful therapy regimes are designed to gain control, suppress inflammation but not cure ${ }^{(2-5)}$.

Chronic lower airway disease is characterized by chronic inflammation which may accompany remodelling events leading to impaired mucosal function. Such changes have been well characterized in the lower airway during progression of chronic diseases such as asthma, which is associated with the release of inflammatory mediators and growth factors and irreversible airway wall thickening ${ }^{(6)}$. However, the remodelling changes which occur during CRS are less well defined.

Inflammation, epithelial fibrosis and basement membrane thickening (BMT) have been shown to be associated with CRS and may be detected using histopathology ${ }^{(4,7)}$. Upper airway remodelling changes have also been shown to be associated with higher prevalence of co-morbid asthma and aspirin sensitivity 
in CRS patients. These changes are usually indicative of advanced disease ${ }^{(8-11)}$ and greater treatment requirements ${ }^{(12)}$. The identification of early mediators of remodelling may aid in the prognosis and appropriate treatment regimes in CRS.

Extracellular matrix proteins (ECM) are involved in physical scaffolding, homeostasis and regulation of inflammation of the airway mucosa ${ }^{(13)}$. Periostin is induced by IL-4 and IL-13 secreted from airway epithelial cells, resulting in the infiltration of eosinophils and mediating fibrosis ${ }^{(14)}$. Greater periostin production has been observed in the basement membranes, nasal polyps and infiltrating cells of patients with CRSWNP and aspirin induced asthma ${ }^{(15)}$. Expression of fibulin-1, fibronectin and collagen in the lower airway has been shown to be associated with asthma ${ }^{(13,16-22)}$. This study aimed to describe the expression of four ECM proteins, periostin, fibulin-1, fibronectin and collage$\mathrm{nIV}$ in CRS; these proteins have previously been implicated in remodelling changes in the lower airway $(14,15,18,20,23)$.

\section{Materials and methods}

\section{Study design}

A cross-sectional study of patients undergoing endoscopic sinus surgery(ESS) at a tertiary Rhinology practice was performed. Demographic data, smoking status, asthma and structured histopathology ${ }^{(4)}$ were recorded prior to data collection. The study had ethics approval from the local institutional ethics review board (LNR/13/SVH/353).

\section{Patient population}

Consecutive consenting patients who underwent endoscopic sinus surgery through a tertiary referral clinic were reviewed. All patients had inflammation identified by histopathology and were grouped according to the presence of remodelling changes as defined by basement membrane thickening (BMT) and subepithelial fibrosis. Patients were divided into three groups, those with only inflammation (controls), those with inflammation and BMT, but no fibrosis, and those who had inflammation, BMT and subepithelial fibrosis. We do not have biopsies from patients with normal mucosa as a separate control group, as our study aims to look at the expression of ECM proteins and their relationship to remodelling of mucosa within CRS patients.No patient used intranasal spray or oral corticosteroids for 4 weeks prior to surgery. Prior cumulative oral corticosteroid use was not accounted for. No patients were taking other immunosuppressive medication. Other medication use was not recorded. Demographic data including age, gender, smoking status, asthma and prior nasal surgeries was recorded. A smoker was defined as a regular current user, or having smoked within the past 12 months. An asthmatic was a person having clinical symptoms of a chronic inflammatory airway disorder needing an inhaled beta-agonist or inhaled prophylactic corticosteroid. Information regarding any previous nasal surgeries was recorded. The pres-
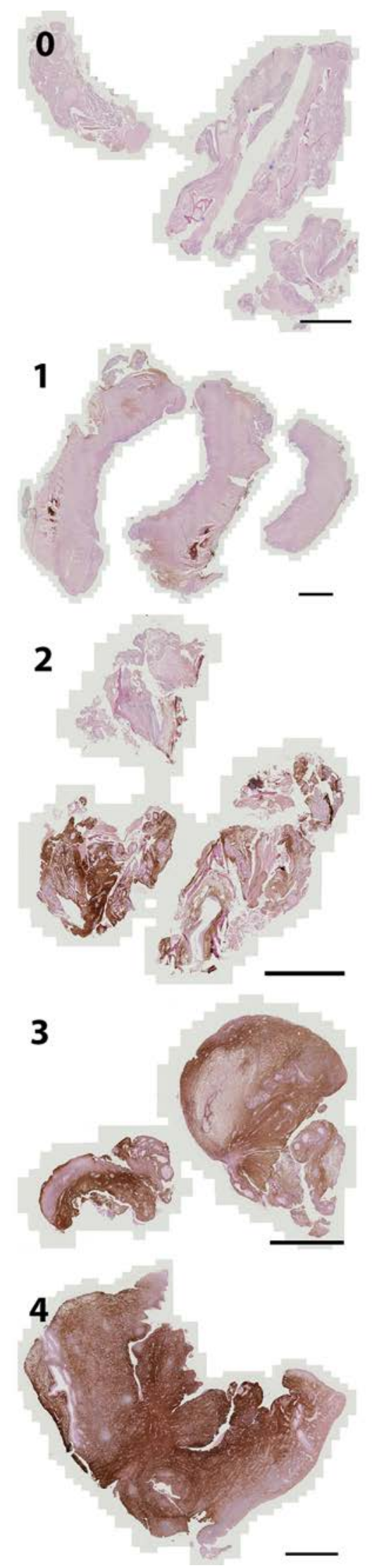

Figure 1. Grading of area of tissue stained positive for periostin by immunohistochemistry (0- No staining, 1-<25\% area stained, 2- 25-50\%, 3-50-75\%, 4- 75-100\%), using an overall view of each slide (the line represents a scale of $2 \mathrm{~mm}$ ). 

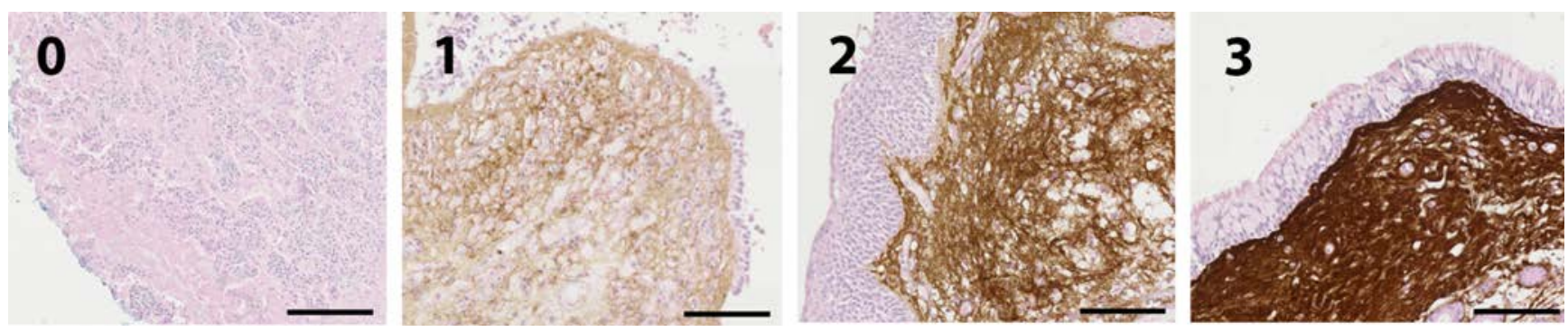

Figure 2. Grading of intensity of staining of periostin by immunohistochemistry (0- No staining, 1- light brown, 2- medium brown, 3- dark brown), using selected fields of view (the line represents a scale of $100 \mu \mathrm{m}$ ).

ence of polyps was noted by endoscopic examination.

\section{Remodelling and tissue characterisation}

Intraoperative mucosal specimens were taken from the ethmoid sinus and underwent standard haematoxylin and eosin (H\&E) staining. Ethmoid mucosa was chosen to best represent the disease process and was selected regardless if simply oedematous or polypoid ${ }^{(24)}$. Structured histopathology reporting was performed for all patients, based on a previously reported format ${ }^{(4)}$. Tissue eosinophilia was defined by tissue eosinophil count (>10 per HPF (HPF, 400x), in 2 or more fields) ${ }^{(25)}$. Remodelling was defined by significant basement membrane thickening $(>7.5 \mu \mathrm{m})$ measured at the site of greatest thickening, and the presence of subepithelial fibrosis, using polarized light to identify areas of excess collagen deposition ${ }^{(4)}$. These changes have been demonstrated in CRS with greater treatment implications $(7,12)$.

Immunohistochemical staining for periostin, fibulin-1, fibronectin, collagenIV was performed on serial $5 \mu \mathrm{m}$ thick paraffin embedded formalin fixed sinus mucosa. Fibulin-1 and periostin staining was performed following the protocol described previously by Jaffar et al. ${ }^{(26)}$ while fibronectin and collagen IV staining was performed using a protocol adapted from Faiz et al. ${ }^{(27)}$ with slight modifications. In summary, the sections were deparaffinized and rehydrated through xylene and decreasing concentrations of ethanol ( $2 \times 100 \%, 95 \%, 70 \%, 50 \%$ ethanol) into deionized water prior to antigen retrieval. No antigen retrieval was required for fibronectin, periostin and fibulin- 1 while collagenIV required treatment for 30 mins in $0.5 \%$ Trypsin in PBS solution at $37^{\circ} \mathrm{C}$ followed by $3 \times 5$ minute washes in deionised water. The sections were incubated with peroxidase blocking solution (Dako, Glostrup, Denmark) followed by non-immune protein block (Dako). Primary antibody (periostin: $0.5 \mu \mathrm{g} / \mathrm{mL}$, fibulin-1: $0.05 \mu \mathrm{g} / \mathrm{mL}$, fibronectin: $0.2 \mu \mathrm{g} / \mathrm{mL}$ and collagenIV: 1.0 $\mu \mathrm{g} / \mathrm{mL}$ ) and isotype control antibody (same concentration as the respective primary antibodies) diluted in Antibody Diluent (Dako) on serial sections were then incubated for 2 hours at $37^{\circ} \mathrm{C}$ (fibulin- 1 and periostin) or overnight at $4^{\circ} \mathrm{C}$ (Fibronectin and CollagenIV) before being washed 5 times in TBS-T for 3 minutes each, followed by incubation in horseradish peroxidase (HRP)-conjugated secondary antibody (Dako) for 45 minutes in an incubator at $37^{\circ} \mathrm{C}$. The sections were then washed 5 times in TBS-T for 3 minutes each and the 3, 3'- Diaminobenzidine (DAB) chromogen was applied for 10 minutes. Following DAB incubation the sections were washed 5 times in deionized water and then counterstained by immersion in Mayer's haematoxylin (Sigma Aldrich, St Louis, MI, USA) for 5 minutes. After washing in tap water for 2 minutes the sections were then dehydrated through $70 \%$ ethanol for 30 secs, counterstained with eosin $Y$ for 1 minute, quick dips in 95\%,100\% and 100\% ethanol and 2 changes of xylene prior to coverslipping with dibutyl phthalate in xylene (DPX) organic mounting media (Asia Pacific Specialty Chemicals, Seven Hills, NSW, Australia).

Images were captured using a Wide-field FL and TL microscope ZEISS Axio Scan.Z1 Slide Scanner (Zeiss, Oberkochen, Germany). The immunostained tissue was scanned at 20x magnification and a whole brightfield tissue image was stitched together from the individual serial images using ZEN software (Zen 2012, Carl Zeiss Microscopy $\mathrm{GmbH}$ ).

\section{Scoring system}

The slides for each stain were viewed and scored independently by two blinded observers. A single view of the entire tissue section was used to assess the Area (A) of the tissue stained positive for each ECM protein, and scored on a 5 point ordinal scale(0- No staining, $1-<25 \%$ area stained, 2- 25-50\%, 3- 50-75\%, 4- 75-100\%) (Figure1).

The intensity (I) of staining of each ECM protein was scored using a 4 point ordinal reference scale ( 0 - No staining, 1 - light brown, 2- medium brown, 3- dark brown) (Figure2). The intensity score focused on the intensity of stain at the level of the basement membrane and in the submucosal region, as these were our areas of interest. All slides were first randomly viewed before areas representative of each level of intensity were chosen for the scale. Three random fields (at 35\% zoom on a 20x magnified image) in which there was a good view of the epithelium, the basement membrane and the submucosa were chosen for each 
slide and scored independently by the two blinded observers. Fields of view covering the same three areas of each patient's tissue sections were scored for all the four stains.

An overall 'Grade of staining' $(G)$ was assigned to each slide by multiplying Area $x$ Intensity $(G=A x I)$ (Grade: $0-12,0$ being no staining and 12 being the strongest staining). These grades were predetermined prior to assessment.

\section{Statistical analysis}

Statistical analysis was performed using IBM ${ }^{\otimes}$ SPSS Statistics version 20.0. Age was parametric and presented as mean ( \pm standard deviation [SD]) and analysis was an ANOVA between groups. Descriptive data are reported as percentages, Kendall's tau-B was used for relationships between ordinal values and the Chi-square test was used for nominal variables. The grade of staining was ordinal and assessed with Kendall's tau-B. The intraclass correlation coefficient (two-way mixed effect model) was used to assess reliability of scoring between the two independent reviewers. Probability values ( $p$-value) $\leq 0.05$ were considered statistically significant.

\section{Results}

\section{Demographics}

Sixty-five patients, $47.67 \pm 13.4$ years, $44.6 \%$ female, were assessed. Half (50.8\%) were asthmatic, $6.2 \%$ were smokers, $60 \%$ had prior sinonasal surgery, $46.2 \%$ had nasal polyps and tissue eosinophilia was present in $56.9 \%$ of patients. The baseline differences between the three groups are described in Table1. Asthma status was similar across the groups (47.1\% v $60 \%$ v $45.5 \%, p=0.56$ ), as was smoking status ( $0 \%$ v $12 \%$ v $4.5 \%$, $\mathrm{p}=0.27)$. A number of patients had prior surgery $(82.0 \% \vee 52.0 \%$ v 54.5\%, $\mathrm{p}=0.11)$, and tissue eosinophilia $>10 / \mathrm{HPF}(47.1 \% \mathrm{v}$ $60.0 \%$ v $63.6 \%, p=0.56$ ), although the distribution across groups was not significant.

Tissue eosinophilia >10/HPF was significantly associated with the presence of polyps (83.3\% of polyps having eosinophilia v $34.3 \%$ of non-polyps with eosinophilia, $p<0.01$ ) and asthma(62.2\% of asthmatics having eosinophilia $v 35.7 \%$ of nonasthmatics with eosinophilia, $p=0.04$ ). The frequency of prior surgery was higher in patients with polyps (73.3\%of revision patients had polyps $v 48.6 \%$ of primary surgical cases, $p=0.05$ ) but not significantly associated with tissue eosinophilia $(67.6 \%$ of revision patients had tissue eosinophilia vs $50.0 \%$ without, $\mathrm{p}=0.15$ )(Table3).

\section{Association between grade of staining and remodelling changes}

Grade of expression of periostin (Strong: $47.1 \%$ v 48.0\% v 68.2\%, $\mathrm{p}=0.05$ ) was significantly associated with remodelling changes, however, it was similar between the groups for fibulin-1 (Strong: $47.1 \%$ v $36.0 \%$ v $36.4 \%, p=0.80$ ), fibronectin(Strong: $52.9 \%$ v
Table 1. Allocation of baseline demographics between groups based on remodelling.

\begin{tabular}{|lcccc} 
& \multicolumn{3}{c}{ Remodelling changes \% (n) } & p value \\
& $\begin{array}{c}\text { Only in- } \\
\text { flammation } \\
\text { (controls) }\end{array}$ & $\begin{array}{c}\text { Inflamma- } \\
\text { tion+ } \\
\text { BMT+ } \\
\text { No fibrosis }\end{array}$ & $\begin{array}{c}\text { Inflamma- } \\
\text { tion+ } \\
\text { BMT+ }\end{array}$ & \\
Fibrosis+ & \\
\hline $\mathrm{n}$ & 17 & 25 & 22 & \\
\hline Age & 48.72 & 48.45 & 47.13 & 0.91 \\
\hline Gender (\%F) & $52.9 \%(9)$ & $48.0 \%(12)$ & $36.4 \%(8)$ & 0.55 \\
\hline Asthma & $47.1 \%(8)$ & $60.0 \%(15)$ & $45.5 \%(10)$ & 0.55 \\
\hline Smokers & $0 \%(0)$ & $12.0 \%(3)$ & $4.5 \%(1)$ & 0.27 \\
\hline Polyps present & $41.2 \%(7)$ & $44.0 \%(11)$ & $54.5 \%(12)$ & 0.66 \\
\hline Tissue eosinop- & $47.1 \%(8)$ & $60.0 \%(15)$ & $63.6 \%(14)$ & 0.56 \\
hilia >10/HPF & $82.4 \%(14)$ & $52.0 \%(13)$ & $54.45 \%(12)$ & 0.11 \\
\hline Prior Surgery & & & & \\
\hline
\end{tabular}

Table 2. Association of grade of expression of extracellular matrix proteins with remodelling changes (\% displayed is the proportion of patients with a strong staining grade 7-12). Analysis was performed as a Kendall-Tau B with all 0-12 ordinal categories/grades of staining expression. Sub-grouping is for demonstration of summary data only.

\begin{tabular}{|c|c|c|c|c|}
\hline \multirow[t]{2}{*}{ ECM protein } & \multicolumn{3}{|c|}{ Remodelling changes $\%$ (n) } & \multirow{2}{*}{$\begin{array}{l}\text { p value } \\
\text { (Ken- } \\
\text { dall's } \\
\text { tau-B) }\end{array}$} \\
\hline & $\begin{array}{l}\text { Only in- } \\
\text { flammation } \\
\text { (controls) }\end{array}$ & $\begin{array}{c}\text { Inflamma- } \\
\text { tion+ } \\
\text { BMT+ } \\
\text { No fibrosis }\end{array}$ & $\begin{array}{c}\text { Inflamma- } \\
\text { tion+ } \\
\text { BMT+ } \\
\text { Fibrosis+ }\end{array}$ & \\
\hline Periostin & $47.1 \%(8)$ & $48.0 \%(12)$ & $68.2 \%(15)$ & 0.05 \\
\hline Fibulin-1 & $47.1 \%(8)$ & $36.0 \%$ (9) & $36.4 \%(8)$ & 0.80 \\
\hline Fibronectin & $52.9 \%$ (9) & $56.0 \%(14)$ & $50.0 \%(11)$ & 0.74 \\
\hline CollagenIV & $17.6 \%(3)$ & $20.0 \%(5)$ & $28.6 \%(6)$ & 0.87 \\
\hline
\end{tabular}

$56.0 \%$ v $50.0 \%, \mathrm{p}=0.74$ ) and collagenIV (Strong: $17.6 \%$ v $20.0 \% \mathrm{v}$ 28.6\%, $\mathrm{p}=0.87$ )(Table2).

Association of grade of staining with tissue eosinophilia Both periostin (Strong: 67.6\% with tissue eosinophilia v 39.3\% without, $\mathrm{p}=0.01$ ) and fibronectin (Strong: $67.6 \%$ v $32.1 \%$, $\mathrm{p}=0.05$ ) showed significantly increased staining in patients with tissue eosinophilia, although fibulin-1 (Strong: 37.8\% v 42.9\%, $\mathrm{p}=0.81$ ) and collagenIV (Strong: $24.3 \%$ v $18.5 \%, \mathrm{p}=0.41$ ) were not found to differ (Table3).

\section{Intra-class correlation coefficient (ICC)}

There was good agreement between the two independent observers; ICC for periostin (0.90), fibulin-1 (0.77), fibronectin 
Table 3. Correlation of Tissue Eosinophilia >10/HPF with baseline demographics and strong grade of expression of extracellular matrix proteins.

\begin{tabular}{|c|c|c|c|}
\hline \multicolumn{4}{|c|}{ Tissue eosinophilia \%(n) } \\
\hline & $<10 / \mathrm{HPF}$ & $>10 / \mathrm{HPF}$ & p-value \\
\hline$n$ & 28 & 37 & \\
\hline Age & $45.37( \pm 13.43)$ & $49.42( \pm 13.32)$ & 0.23 \\
\hline $\begin{array}{l}\text { Gender (\%fe- } \\
\text { male) }\end{array}$ & $46.4 \%(13)$ & $43.2 \%(16)$ & 0.80 \\
\hline Asthma & $35.7 \%(10)$ & $62.2 \%(23)$ & 0.04 \\
\hline Smoking & $3.6 \%(1)$ & $8.1 \%(3)$ & 0.45 \\
\hline Prior Surgery & $50.0 \%(14)$ & $67.6 \%(25)$ & 0.15 \\
\hline BM thickening & $64.3 \%(18)$ & $78.4 \%(29)$ & 0.21 \\
\hline Fibrosis & $28.6 \%(8)$ & $37.8 \%(14)$ & 0.43 \\
\hline Polyps present & $17.9 \%(5)$ & $67.6 \%(25)$ & $<0.01$ \\
\hline $\begin{array}{l}\text { Periostin } \\
\text { ( } \geq \text { strong grade) }\end{array}$ & $39.3 \%(11)$ & $67.6 \%(25)$ & 0.01 \\
\hline $\begin{array}{l}\text { Fibulin-1 } \\
\text { ( } \geq \text { strong grade) }\end{array}$ & $42.9 \%(12)$ & $37.8 \%(14)$ & 0.80 \\
\hline $\begin{array}{l}\text { Fibronectin } \\
\text { ( } \geq \text { strong grade) }\end{array}$ & $32.1 \%(9)$ & $67.6 \%(25)$ & 0.05 \\
\hline $\begin{array}{l}\text { CollagenIV } \\
\text { ( } \geq \text { strong grade) }\end{array}$ & $18.5 \%(5)$ & $24.3 \%(9)$ & 0.41 \\
\hline
\end{tabular}

Table 4. Association of grade of expression of extracellular matrix proteins with remodelling changes in primary cases (\% displayed is the proportion of patients with a strong staining grade 7-12). Analysis was performed as a Kendall-Tau B with all 0-12 ordinal categories/grades of staining expression. Sub-grouping is for demonstration of summary data only.

\begin{tabular}{|lcccc|}
\hline ECM protein & \multicolumn{2}{c}{ Remodelling changes in primary cases } & $\begin{array}{c}\text { p value } \\
\text { (Ken- }\end{array}$ & $\begin{array}{c}\text { (n) } \\
\text { dall's } \\
\text { Only in- } \\
\text { tau-B) }\end{array}$ \\
\hline $\begin{array}{c}\text { flammation } \\
\text { (controls) }\end{array}$ & $\begin{array}{c}\text { Inflamma- } \\
\text { tion+ } \\
\text { BMT+ } \\
\text { No fibrosis }\end{array}$ & $\begin{array}{c}\text { Inflamma- } \\
\text { tion+ } \\
\text { BMT+ } \\
\text { Fibrosis+ }\end{array}$ & \\
\hline Periostin & $33.3 \%(1)$ & $33.3 \%(4)$ & $70.0 \%(7)$ & 0.05 \\
\hline Fibulin-1 & $66.7 \%(2)$ & $25.0 \%(3)$ & $40.0 \%(4)$ & 0.50 \\
\hline Fibronectin & $0 \%(0)$ & $50.0 \%(6)$ & $50.0 \%(5)$ & 0.53 \\
\hline CollagenIV & $33.3 \%(1)$ & $16.7 \%(2)$ & $33.3 \%(3)$ & 0.77 \\
\hline
\end{tabular}

(0.91), collagenIV (0.91) with $p<0.01$.

\section{Analysis on primary (unoperated) surgical cases}

A separate sub-analysis was done on only primary surgical cases $(n=26)$, with age $42.52 \pm 12.88,42.3 \%$ female. Asthma was present in $42.3 \%$, smoking (11.5\%), polyps (30.8\%), tissue eosinophilia $>10 /$ HPF (46.2\%) of primary cases. Tissue eosinophilia $>10 /$ HPF was significantly associated with polyps $(50.0 \%$ with tissue
Table 5. Allocation of baseline demographics between groups based on primary cases versus previously operated cases.

\begin{tabular}{|lccc|}
\hline & $\begin{array}{c}\text { Primary cases } \\
\%(\mathbf{n})\end{array}$ & $\begin{array}{c}\text { Previous } \\
\text { surgeries } \%(\mathbf{n})\end{array}$ & p-value \\
\hline $\mathrm{N}$ & 26 & 39 & \\
\hline Age & $42.52( \pm 12.88)$ & $51.10( \pm 12.80)$ & 0.75 \\
\hline Gender (\%f) & $42.3 \%(11)$ & $46.2 \%(18)$ & 0.09 \\
\hline Asthma & $42.3 \%(11)$ & $56.4 \%(22)$ & 0.30 \\
\hline Smoking & $11.5 \%(3)$ & $2.6 \%(1)$ & $0.29^{*}$ \\
\hline BM thickening & $84.6 \%(22)$ & $64.1 \%(25)$ & 0.07 \\
\hline Fibrosis & $38.5 \%(10)$ & $30.8 \%(12)$ & 0.52 \\
\hline $\begin{array}{l}\text { Tissue eosinop- } \\
\text { hilia }>10 / \mathrm{HPF}\end{array}$ & $46.2 \%(12)$ & $64.1 \%(25)$ & 0.15 \\
\hline $\begin{array}{l}\text { Presence of } \\
\text { polyps }\end{array}$ & $30.8 \%(8)$ & $56.4 \%(22)$ & 0.04 \\
\hline
\end{tabular}

*Fisher's Exact Test, given expected cell count less than 5

Table 6. Association of grade of expression of extracellular matrix proteins with primary cases and those who had previous surgery(\% displayed is the proportion of patients with strong staining grade 7-12). Analysis was performed as a Kendall-Tau B with all 0 -12 ordinal categories/grades of staining expression. Sub-grouping is for demonstration of summary data only.

\begin{tabular}{|lccc|}
\hline ECM protein & $\begin{array}{c}\text { Primary cases } \\
\%(\mathbf{n})\end{array}$ & $\begin{array}{c}\text { Previous } \\
\text { Surgery } \%(\mathbf{n})\end{array}$ & $\begin{array}{c}\text { p value } \\
\text { Kendall's tau-B }\end{array}$ \\
\hline Periostin & $50.0 \%(13)$ & $59.0 \%(23)$ & 0.98 \\
\hline Fibulin-1 & $38.5 \%(10)$ & $41.0 \%(16)$ & 0.52 \\
\hline Fibronectin & $42.3 \%(11)$ & $59.0 \%(23)$ & 0.27 \\
\hline CollagenIV & $24.0 \%(6)$ & $20.5 \%(8)$ & 0.49 \\
\hline
\end{tabular}

eosinophilia $v 14.3 \%$ without, $\mathrm{p}=0.05)$, basement membrane thickening (100\% v 71.4\% $\mathrm{p}=0.04])$ and fibrosis $(58.3 \% \vee 21.4 \%$, $\mathrm{p}=0.05)$.

The grade of expression of the four ECM proteins, showed similar relationships to the overall analysis, with periostin (Strong: $33.3 \%$ v 33.3\% v 70.0\%, p=0.05), fibulin-1(Strong: $66.7 \%$ v $25.0 \%$ v $40.0 \%, p=0.50)$, fibronectin ( $\%$ v 50.0\% v 50.0\%, $p=0.53)$ and collagenIV (Strong: 33.3\% v 16.7\% v 33.3\%, p=0.77)(Table 4). Also, higher periostin grade was significantly associated with tissue eosinophilia (Strong: 66.7\% with tissue eosinophilia v 35.7\% without, $\mathrm{p}<0.01)$. There were no significant differences in ECM protein expression between primary and previously operated cases (Table 5 and 6).

\section{Discussion}

Remodelling of the respiratory mucosa is a feature of patients 
with airway disease ${ }^{(2)}$. Chronic airway remodelling represents an aberrant repair cycle with the interaction between many cell types, including epithelial cells, fibroblasts and smooth muscle cells. The "epithelial-mesenchymal trophic unit" is thought to drive chronic remodelling in asthma. In asthma, the airway wall is thickened with epithelial dysplasia, angiogenesis, increased extracellular matrix (ECM) deposition, and increased airway smooth muscle (ASM) mass. These changes are thought to contribute to increased airflow obstruction that is only partially reversed by therapy and may lead to an element of fixed airflow obstruction. The severity of asthma correlates with the presence of remodelling ${ }^{(28-30)}$.

There are several articles in literature that describe increased inflammatory cell infiltrate and increased thickness of the basement membrane as part of remodelling changes in the asthmatic airway as compared to normals. Ward et al, in 2002, described subepithelial reticular basement membrane thickening and inflammatory cells significantly increased in asthmatics as compared to normals ${ }^{(30)}$. When compared with healthy volunteers, Chetta et al found that patients with asthma had significantly higher levels of mast cells, activated eosinophils, basement membrane thickening and vascular area ${ }^{(31)}$. In 2007, Bourdin et al. used two different techniques to measure the reticular basement membrane, and found that there was significant thickening of the basement membrane, not just in severe asthma, but even in mild asthma as compared to normal healthy controls ${ }^{(32)}$. Increased expression of periostin ${ }^{(14)}$, fibulin-1 ${ }^{(18,23)}$, fibronectin ${ }^{(17,20)}$ and decreased collagenIV ${ }^{(33,34)}$ have also been associated with remodelling changes in the lower airway of asthmatics as compared to normals. As our study aims to look at the expression of ECM proteins and their relationship to remodelling of mucosa in CRS patients, we did not study mucosa from normal patients as a separate control group.

While remodelling exists in CRS ${ }^{(7)}$ its impact on disease outcomes is less clear than in the asthma literature. Prior studies have demonstrated a relationship between BM thickening and duration of symptoms ${ }^{(35)}$, the presence of eCRS ${ }^{(7)}$ and the need for more ongoing therapy ${ }^{(12)}$.

There is prior evidence in literature that periostin plays an important role in inflammation and remodelling of the nasal mucosa in CRS, through the activation and chemotaxis of eosinophils ${ }^{(15,36)}$. Ishida et al. described periostin positive staining in the basement membrane, ECM, inflammatory cells and tissue from nasal polyps by immunohistochemistry. Their study also found significantly higher levels of periostin in tissue from patients with allergic rhinitis, CRSwNP and aspirin-induced asthma than in controls ${ }^{(15)}$.

The 'grade' of expression used in this study is a reflection both of the area of the tissue stained positive for the protein, as well as the intensity of the stain. A higher grade of periostin expression was found in the group with both BMT and fibrosis. Increased periostin was significantly associated with the presence of remodelling changes, in keeping with known literature.

The evidence that periostin concentration, in tissue, serum or sputum, and the numbers of eosinophils are closely related is supported by the high expression of periostin in patients with tissue eosinophilia ${ }^{(37,38)}$. The cause-effect relationship of periostin and eosinophilia is something of a causality dilemma. Johansson et al. identified $\mathrm{aM} \beta 2$, a periostin receptor which is expressed by activated eosinophils ${ }^{(39)}$. Li et al. have suggested that an autocrine loop involving periostin and eosinophils could lead to a vicious cycle of signalling and its effects ${ }^{(40)}$. The association of periostin with tissue eosinophilia and remodelling changes may provide an early indication of the severity of the disease ${ }^{(7)}$. Tissue eosinophil status and remodelling were used to assess groups rather than polyp status. The phenotype of severe oedema, polypoid mucosa and frank polyps is ambiguous and difficult to define, especially in the revision patient and was avoided.

Periostin, originally named osteoblast specific factor, may also have a role in the neo-osteogenesis which occurs in CRS ${ }^{(41)}$. Tissue eosinophilia has also been shown to be associated with bone remodelling changes ${ }^{(42)}$. Matsusaka et al. recently reported high concentrations of serum periostin correlated with a specific phenotype of late onset eosinophilic asthma unresponsive to inhaled corticosteroids, and associated with CRSwNP and olfactory dysfunction ${ }^{(43)}$. Detection of serum or sputum periostin may be an easier way of identifying patients with a more resistant phenotype ${ }^{(37)}$.

The grade of expression was similar between groups for fibulin-1, fibronectin and collagenIV. Lau et al. have reported increased levels of fibulin- 1 in asthmatics and shown its potential role in airway remodelling ${ }^{(18)}$. Increased levels of fibronectin have been reported in the airways of patients with asthma (17). The role of eosinophil secreted profibrotic cytokines like TGF- $\beta$ and the deposition of collagen have been reported ${ }^{(16,19-21)}$. Van Bruaene et al have reported early collagen deposition in sinus disease even before the advent of inflammation ${ }^{(44)}$.

Fibrosis is typically measured by the histological assessment of the overall expression of all collagens. There are at least 29 different types of collagens, each of which has multiple genetically distinct alpha chains. In this study, we looked at one specific type of collagen, collagenIV, found in basement membranes, based on the investigators' previous publications in which collagenIV was found to be significantly decreased in patients with asthma ${ }^{33,34)}$. Other collagen subtypes are likely to account for fibrosis where collagenIV was not expressed.

Van Zele et al. describe the different expression of cytokines in recurrent versus non-recurrent CRSwNP ${ }^{(45)}$. In 2016, Tomassen et al. described a wide variety of endotypes of CRS based on inflammatory profiles ${ }^{(46)}$.

While extracellular matrix proteins are normally present in 
tissues, only periostin showed statistically significant association with remodelling and tissue eosinophilia. This finding is consistent with published literature, and supports evidence that increased expression of periostin is likely to be important in the pathophysiology of CRS. However, the other ECM proteins may have some relationship with remodelling changes but a Type 2 error may exist. Zhang et al. demonstrated a decrease in the expression of periostin in sinus tissue three months after successful therapy, suggesting that periostin expression may reflect disease activity ${ }^{(47)}$. Thus, ECM proteins may have a potential to serve as early biomarkers of remodelling changes in the nasal and sinus mucosa. The ease of detection of ECM proteins, especially periostin, has improved over recent years, with immunohistochemistry, microarray analysis of gene expression, detection of serum and sputum expression all available, making the ECM proteins valuable in their role both as prognostic indicators and future targets for modifying disease.

Although this study demonstrated a relationship with periostin expression and remodelling, changes in expression of the ECM proteins with disease progression or as a response to therapy are areas of interest yet to be addressed. Such mucosal remodelling changes might predict a degree of 'fixed' mucosal change and limited reversibility of the disease process. Early therapy may be warranted in patients at risk of mucosal remodelling, and such an approach might explain the more favourable outcomes in patients who are treated more aggressively in their disease course ${ }^{(48)}$. Further studies involving a larger number of patients, with follow up, would be required to explore the influence of ECM proteins on disease management and/or early detection.

\section{Conclusion}

Extracellular matrix proteins, especially periostin, are increasingly being studied as mediators of inflammation and remodelling, both in the lower and the upper airway. A higher grade of periostin expression was significantly associated with the presence of remodelling changes and tissue eosinophilia. ECM proteins such as periostin may serve as early prognostic indicators of eosinophil activation and remodelling, heralding more aggressive therapy or as targets for disease modifying strategies.

\section{Acknowledgements}

Nil funding sources to declare.

\section{Authorship contribution}

JAE: study design, data collection and analysis, manuscript draft and edits; JMC: data collection and analysis, manuscript draft and edits; BGO: study design, data collection and analysis, manuscript edits, expert opinion; RAO: data collection and analysis; GT: data collection and analysis, manuscript draft and edits; JH: data collection and analysis; ARH: data collection and analysis; JR: study design, data collection and analysis, manuscript edits, expert opinion; RS: manuscript edits, expert opinion; RJH: conceptualization, study design, data collection and analysis, manuscript edits, expert opinion.

\section{Conflict of interest}

RJH is consultant with Medtronic, Olympus and NeilMed pharmaceuticals. Research grant funding received from Meda Pharmaceuticals and Stallergenes. Has been on the speakers' bureau for Glaxo-Smith-Kline and Arthrocare. RS is a consultant with Medtronic and Takeda pharmaceuticals.

\section{References}

1. Fokkens WJ, Lund V, Mullol J, et al. EPOS 2012: European position paper on rhinosinusitis and nasal polyps 2012. A summary for otorhinolaryngologists. Rhinology. 2012; 50(1): 1-12.

2. Jiang $N$, Kern RC, Altman KW Histopathological evaluation of chronic rhinosinusitis: a critical review. Am J Rhino Allergy. 2013; 27(5): 396-402.

3. Snidvongs K, Chin D, Sacks R, Earls P, Harvey RJ. Eosinophilic rhinosinusitis is not a disease of ostiomeatal occlusion. Laryngoscope. 2013; 123(5): 1070-4.

4. Snidvongs K, Lam M, Sacks R, et al. Structured histopathology profiling of chronic rhinosinusitis in routine practice. Int Forum Allergy Rhinol. 2012; 2(5): 376-85.

5. Chin D, Harvey RJ. Nasal polyposis: an inflammatory condition requiring effective anti-inflammatory treatment. Curr Opin Otolaryngol Head Neck Surg. 2013; 21(1): 23-30.

6. Bergeron C, Tulic MK, Hamid Q. Airway remodelling in asthma: from benchside to clinical practice. Can Respir J. 2010; 17(4) 85-93.

7. Barham HP, Osborn JL, Snidvongs K, Mrad N, Sacks R, Harvey RJ. Remodeling changes of the upper airway with chronic rhinosinusitis. Int Forum Allergy Rhinol. 2015; 5(7): 565-72.

8. Bassiouni A, Chen PG, Wormald PJ. Mucosal remodeling and reversibility in chronic rhinosinusitis. Curr Opin Allergy Clin Immunol. 2013 Feb;13(1):4-12

9. Ponikau JU, Sherris DA, Kephart GM, et al. Features of airway remodeling and eosinophilic inflammation in chronic rhinosinusitis: is the histopathology similar to asthma? J Allergy Clin Immunol. 2003; 112(5): 877-82.

10. Togias A. Rhinitis and asthma: evidence for respiratory system integration. J Allergy Clin Immunol. 2003; 111(6): 1171-83

11. Watelet JB, van Zele T, Gjomarkaj M, et al. Tissue remodelling in upper airways: where is the link with lower airway remodelling? Allergy. 2006; 61(11): 1249-58.
12. Do TQ Barham HP, Earls $P$, et al. Clinical implications of mucosal remodeling from chronic rhinosinusitis. Int Forum Allergy Rhinol. 2016; 6(8): 835-840

13. Frantz C, Stewart KM, Weaver VM. The extracellular matrix at a glance. J Cell Sci. 2010; 123(Pt 24): 4195-200.

14. Takayama G, Arima K, Kanaji T, et al. Periostin: a novel component of subepithelial fibrosis of bronchial asthma downstream of IL-4 and IL-13 signals. J Allergy Clin Immunol. 2006; 118(1): 98-104.

15. Ishida A, Ohta N, Suzuki Y, et al. Expression of pendrin and periostin in allergic rhinitis and chronic rhinosinusitis. Allergol Int. 2012; 61(4): 589-95.

16. Chung SW, Park $\mathrm{H}$, Hong SM, et al. Role of caffeic Acid on collagen production in nasal polyp-derived fibroblasts. Clin Exp Otorhinolaryngol. 2014; 7(4): 295-301.

17. Ge Q, Zeng Q, Tjin G, et al. Differential deposition of fibronectin by asthmatic bronchial epithelial cells. Am J Physiol Lung Cell Mol Physiol. 2015; 309(10): 1093-102. 
18. Lau JY, Oliver BG, Baraket $M$, et al. Fibulin-1 is increased in asthma--a novel mediator of airway remodeling? PLoS One. 2010; 5(10): 13360

19. Little SC, Early SB, Woodard CR, et al. Dua action of TGF-beta1 on nasal-polyp derived fibroblasts. Laryngoscope. 2008; 118(2): 320-4.

20. Moir LM, Burgess JK, Black JL. Transforming growth factor beta 1 increases fibronectin deposition through integrin receptor alpha 5 beta 1 on human airway smooth muscle. J Allergy Clin Immunol. 2008; 121(4): 1034-9.

21. Pawankar R, Nonaka M. Inflammatory mechanisms and remodeling in chronic rhinosinusitis and nasal polyps. Curr Allergy Asthma Rep. 2007; 7(3): 202-8.

22. Tran H, VanDusen WJ, Argraves WS. The selfassociation and fibronectin-binding sites of fibulin-1 map to calcium-binding epidermal growth factor-like domains. J Biol Chem. 1997: 272(36): 22600-6.

23. Ge Q, Chen L, Jaffar J, et al. Fibulin 1 C peptide induces cell attachment and extracelIular matrix deposition in lung fibroblasts. Sci Rep. 2015; 5: 9496.

24. Ho J, Bailey M, Zaunders J, et al. Cellular comparison of sinus mucosa vs polyp tissue from a single sinus cavity in chronic rhinosinusitis. Int Forum Allergy Rhinol. 2015; 5(1): 14-27.

25. Soler ZM, Sauer D, Mace J, Smith TL. Impact of mucosal eosinophilia and nasal polyposis on quality-of-life outcomes after sinus surgery. Otolaryngol Head Neck Surg. 2010; 142(1): 64-71.

26. Jaffar J, Unger S, Corte TJ, et al. Fibulin-1 predicts disease progression in patients with idiopathic pulmonary fibrosis. Chest. 2014; 146(4): 1055-63.

27. Faiz A, Tjin G, Harkness L, et al. The expression and activity of cathepsins $\mathrm{D}, \mathrm{H}$ and $\mathrm{K}$ in asthmatic airways. PLoS One. 2013; 8(3): 57245

28. Chetta A, Marangio E, Olivieri D. Inhaled steroids and airway remodelling in asthma. Acta Biomed. 2003; 74(3): 121-5.

29. Holgate ST, Arshad HS, Roberts GC, Howarth $\mathrm{PH}$, thurner $\mathrm{P}$, Davies DE. A new look at the pathogenesis of asthma. Clin Sci (Lond). 2010; 118(7): 439-50.

30. Ward C, Pais M, Bish R, et al. Airway inflam- mation, basement membrane thickening and bronchial hyperresponsiveness in asthma. Thorax 2002: 57(4): 309-16.

31. Chetta A, Zanini A, Foresi A, et al. Vascular component of airway remodeling in asthma is reduced by high dose of fluticasone. Am J Respir Crit Care Med. 2003; 167(5):751 7.

32. Bourdin A, Neveu D, Vacheir I, Paganin F, Godard P, Chavez P. Specificity of basement membrane thickening in severe asthma. Allergy Clin Immunol. 2007: 119(6):1367-74.

33. Burgess JK, Boustany S, Moir LM, et al. Reduction of tumstatin in asthmatic airways contributes to angiogenesis, inflammation, and hyperresponsiveness. Am J Respir Crit Care Med. 2010; 181(2): 106-15.

34. Weckmann M, Moir LM, Heckman CA, Black JL, Oliver BG, Burgess JK. Lamstatin--a nove inhibitor of lymphangiogenesis derived from collagen IV. J Cell Mol Med. 2012; 16(12): 3062-73.

35. Rehl RM, Balla AA, Cabay RJ, Hearp ML, Pytynia KB, Joe SA. Mucosal remodeling in chronic rhinosinusitis. Am J Rhinol. 2007; 21(6): 651-7.

36. Ohta N, Ishida A, Kurakami K, et al. Expressions and roles of periostin in otolaryngological diseases. Allergol Int. 2014; 63(2): 171-80

37. Bobolea I, Barranco P, Del Pozo V, et al. Sputum periostin in patients with different severe asthma phenotypes. Allergy. 2015 70(5): 540-6.

38. Jia G, Erickson RW, Choy DF, et al. Periostin is a systemic biomarker of eosinophilic airway inflammation in asthmatic patients. Allergy Clin Immunol. 2012; 130(3): 647-654.

39. Johansson MW, Annis DS, Mosher DF. alpha(M)beta(2) integrin-mediated adhesion and motility of IL-5-stimulated eosinophils on periostin. Am J Respir Cell Mol Biol. 2013; 48(4): 503-10.

40. Li W, Gao P, Zhi Y, et al. Periostin: its role in asthma and its potential as a diagnostic or therapeutic target. Respir Res. 2015; 16: 57.

41. Conway SJ, Izuhara K, Kudo Y, et al. The role of periostin in tissue remodeling across health and disease. Cell Mol Life Sci. 2014 71(7): 1279-88.

42. Snidvongs $K$, McLachlan $R$, Chin $D$, et al Osteitic bone: a surrogate marker of eosino- philia in chronic rhinosinusitis. Rhinology 2012; 50(3): 299-305

43. Matsusaka M, Kabata H, Fukunaga K, et al. Phenotype of asthma related with high serum periostin levels. Allergol Int. 2015 64(2): 175-80

44. Van Bruaene N, Bachert C. Tissue remodeling in chronic rhinosinusitis. Curr Opin Allergy Clin Immunol. 2011; 11(1): 8-11.

45. Van Zele T, Holtappels G, Gevaert P, Bachert C. Differences in initial immunoprofiles between recurrent and nonrecurrent chronic rhinosinusitis with nasal polyps. Am J Rhinol Allergy. 2014; 28(3): 192-8.

46. Tomassen P, Vandeplas G, Van Zele T, et al. Inflammatory endotypes of chronic rhinosinusitis based on cluster analysis of biomarkers. J Allergy Clin Immunol. 2016; 137(5): 1449-1456.

47. Zhang W, Hubin G, Endam LM, Al-Mot S, Filali-Mouhim A, Desrosiers M. Expression of the extracellular matrix gene periostin is increased in chronic rhinosinusitis and decreases following successful endoscopic sinus surgery. Int Forum Allergy Rhinol. 2012; 2(6): 471-6.

48. Hopkins C, Rimmer J, Lund VJ. Does time to endoscopic sinus surgery impact outcomes in Chronic Rhinosinusitis? Prospective findings from the National Comparative Audit of Surgery for Nasal Polyposis and Chronic Rhinosinusitis. Rhinology. 2015; 53(1): 10-7.

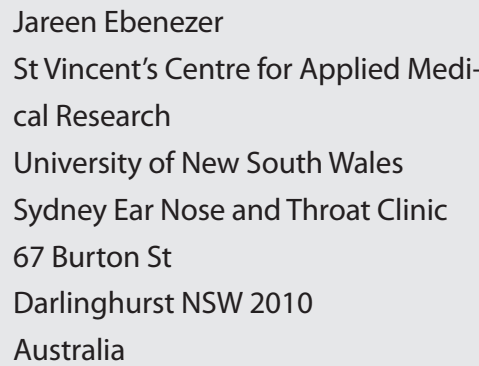

Tel: +61-(0)2-9360-4811

E-mail: jareenebenezer@gmail.com 